\title{
Las epístolas privadas de Nicolás Maquiavelo
}

\author{
Montserrat Casas Nadal
}

Universitat de Barcelona

\section{Rosa Rius Gatell}

Universitat de Barcelona

En tiempos en los que hemos visto decaer el género epistolar, bienvenida sea la nueva edición de las epistolae familiares de Nicolás Maquiavelo.

Septiembre de 2007 tuvo la fortuna de saludar el nacimiento de una nueva traducción en castellano de las cartas del secretario florentino. Epistolario privado, leemos en la cubierta; y en ella, a modo de subtítulo se especifica: Las cartas que nos desvelan el pensamiento y la personalidad de uno de los intelectuales más importantes del Renacimiento. Las cubiertas no siempre indican qué encontraremos en las páginas que «cubren». Éste no es el caso, pues las misivas allí recogidas procuran datos de innegable interés sobre la personalidad global del gran autor florentino y aportan materiales fundamentales para la comprensión histórica de su pensamiento; son, ciertamente, un instrumento imprescindible para comprender las vicisitudes de su carrera política y nos ofrecen valiosos detalles sobre la composición de sus obras. Cuidadosamente traducidas y editadas por Juan Manuel Forte —a quien se debe asimismo una muy interesante introducción-, las cartas que nos brinda La Esfera de los Libros nos muestran un rostro mucho menos conocido del autor. ${ }^{1}$ Una imagen distinta de aquella otra del frío analista político de los tratados.

El epistolario resulta, además, de gran utilidad para el estudio y el análisis de la vida cotidiana y de la mentalidad de la sociedad italiana en una época crucial, como fue el Renacimiento, en la que los estados italianos atravesaron momentos muy difíciles, a causa de la inestabilidad provocada por las continuas guerras y los constantes cambios de régimen político. Ante tal coyuntura, se pone de manifiesto la vulnerabilidad de la población, y Maquiavelo constituye un buen ejemplo de esa frágil estabilidad: el cambio de régimen que se produjo en Florencia en 1512, tras la caída de la república popular, truncó de golpe su brillante carrera política y lo apartó de su cargo en la cancillería florentina.

1. Nicolás MAQUiaVelo, Epistolario privado. Las cartas que nos desvelan el pensamiento y la personalidad de uno de los intelectuales más importantes del Renacimiento. Edición y traducción de Juan Manuel Forte, Madrid: La Esfera de los Libros, 2007. 
Las cartas nos permiten seguir el recorrido vital de Maquiavelo de un modo casi íntimo. El autor nos transmite sus preocupaciones personales y políticas, los detalles de su vida familiar, e incluso su mal humor en los momentos bajos. Nos permiten, también, ser testigos de sus desinhibidas bromas, muestra del carácter abierto, divertido y familiar del autor de El Príncipe.

El epistolario nos permite asimismo conocer de primera mano qué pensaba Maquiavelo sobre los acontecimientos políticos de su época. Resulta muy interesante su visión sobre la actuación de los protagonistas principales, entre ellos, Fernando el Católico, el emperador Carlos V, el rey Luis XII de Francia y, especialmente, el papa Clemente VII; también podemos hacernos una idea de su opinión respecto de las acciones de otros personajes de gran influencia en aquellos momentos, como Fernando de Ávalos, marqués de Pescara, o el duque de Sessa.

La presente edición ha tenido en cuenta las últimas aportaciones de la crítica filológica más reconocida, y ha recogido los últimos descubrimientos de ésta, gracias a los cuales se han modificado diversas partes del texto, así como la datación de algunas cartas. Consta de 118 epístolas, ordenadas cronológicamente, más una en apéndice. De ellas, 84 fueron redactadas por Maquiavelo y son las únicas que, hasta el momento, han llegado hasta nosotros. Las demás se deben a dos de sus principales corresponsales, y amigos, Francesco Vettori, embajador de la república florentina en Roma hasta mayo de 1515 (24 cartas) y el historiador y político Francesco Guicciardini (10 cartas). Como señala Forte en su introducción, en este doble intercambio encontramos los momentos de mayor interés del epistolario.

De este carteo, como ya indicábamos, emerge un Maquiavelo mucho menos conocido: un perfil trazado principalmente por el propio autor, en el que la crónica y el análisis se mezclan con buenas dosis de ironía y de prosa burlesca. Maquiavelo, a diferencia de otros autores de la época, no guardaba una copia de sus cartas, ni escribía con la intención de publicarlas. De ahí, probablemente, el grado de intimidad que emana de muchas de ellas; también de ahí, a buen seguro, algunas de sus recreaciones en lo obsceno y lo grotesco; su recurso constante al amor y al sexo, y las continuas bromas sobre su propia sexualidad, como bien señala Juan Manuel Forte en su introducción.

Las cartas recopiladas abarcan un arco cronológico de tres décadas, desde diciembre de 1497 hasta abril de 1527, año del fallecimiento de Maquiavelo. Recorren, por lo tanto, momentos muy distintos de su vida. Forte, apoyándose en la correspondencia con Vettori y Guicciardini, cree posible dividir el epistolario maquiaveliano en tres períodos diferenciables.

La primera etapa ante res perditas, por utilizar la propia expresión de Maquiavelo, comprende sus años de ejercicio y reflexión como secretario florentino (1498-1512), y de ella se conservan 19 epístolas. Al primer año de esa etapa, el mismo en que empieza a trabajar en la cancillería florentina, se debe la famosa carta del 9 de marzo, en la que Maquiavelo escribía al entonces embajador de Florencia en Roma, Ricciardo Becchi, para darle cumplida noticia de los últimos movimientos de Girolamo Savonarola por mantener su proyecto de 
reforma religiosa y política (carta 3). Poco después de esta carta, Savonarola, crítico implacable del papado fue detenido, torturado y quemado públicamente en la plaza de la Señoría, el 23 de mayo de 1498. Durante esta etapa, la de mayor actividad política de Maquiavelo, sobresalen también los Ghiribizzi (fantasías, divagaciones) a Giovanni Battista Soderini (carta 14; tal vez nunca enviada), que anticipan la cuestión de la fortuna y la racionalidad de la política, que se planteará de nuevo en el poema De la Fortuna; destaca asimismo la epístola a Luigi Guicciardini, en la que encontramos la primera incursión del epistolario en el territorio de lo burlesco (carta 17).

La segunda etapa distinguida por Forte abarca de 1513 a 1515, es decir, los años que siguen al momento en que los Medici reasumieron el poder en Florencia (1512). Maquiavelo fue entonces depuesto de todo cargo público. Alejado de su empleo, multado y obligado a un año de confinamiento, fue posteriormente arrestado y torturado, considerado sospechoso en una conjura antimedicea. Una vez liberado comenzó su retiro en Sant'Andrea in Percussina, a escasos quilómetros de Florencia. "Constreñido por la pobreza», son años de angustia y penuria durante los cuales se intensifica la correspondencia con Francesco Vettori. En ese período, escribe Forte, «hallamos quizá el segmento más intenso, del epistolario, marcado por la desgracia política y personal de ex Secretario» (p. 20). En aquellos momentos, el consuelo moral de Vettori fue, sin duda, de máxima importancia. De esta segunda etapa emerge un Maquiavelo "consumido" por su inactividad, apesadumbrado por las pérdidas sufridas y dispuesto a cualquier cosa con tal de retomar la actividad política al servicio de «estos señores de Medici [...] aunque sólo fuera para arrastrar una piedra» (carta 40); un Maquiavelo obligado a un «ocio forzado», que no podía renunciar a su vocación política. Como él mismo escribía:

Si os pudiera hablar en persona, no podría evitar llenaros la cabeza de lucubraciones, porque la Fortuna ha hecho de tal manera que, no sabiendo razonar ni del arte de la seda, ni del arte de la lana, ni de ganancias o pérdidas, me convenga razonar de los asuntos de estado, y necesariamente tengo que razonar de esto, o hacer voto de silencio (carta 40).

Debemos, no obstante, a esa inactividad no buscada algunas de sus principales obras (en 1513 El Príncipe, y emprendió la redacción de los Discursos sobre la primera década de Tito Livio, que terminó en 1517). Gracias asimismo a ese tiempo ocioso, Maquiavelo nos legó algunas joyas literarias, entre las cuales destaca la carta dirigida a Francesco Vettori el 10 de diciembre de 1513. En ella su autor anunciaba al amigo haber escrito De principatibus. Reconocida como una de las epístolas más importantes de la literatura italiana, nos permitimos citarla por extenso:

Avanzada la tarde, me vuelvo a casa y entro en mi despacho. Y en el umbral me despojo de mis vestidos cotidianos, llenos de fango y lodo, y me visto con ropas nobles y curiales. Entonces, dignamente ataviado, entro en las cortes de los hombres antiguos, donde, amablemente recibido por ellos, me deleito con 
ese alimento que es sólo para mí, y para el que yo nací. Y no me avergüenzo de hablar con ellos, y de preguntarles por las razones de sus acciones. Y ellos, por su humanidad, me responden. Y durante cuatro horas no siento ningún aburrimiento, me olvido de toda ambición, no temo la pobreza, no me da miedo la muerte: me transfiero enteramente donde están ellos. Y como Dante dice que no hay saber si no se guarda lo que se ha comprendido, yo he anotado lo que he sacado con su conversación, y he compuesto un opúsculo, De principatibus, en el que profundizo cuanto puedo en las dificultades de esta materia; razonando sobre qué es un principado, de cuántos tipos hay, cómo se adquieren, cómo se mantienen, por qué se pierden (carta 40).

De los años que transcurren entre 1516 y 1519 poco se sabe, salvo el bajo estado de ánimo de Maquiavelo que reflejan las cartas que dirige a su sobrino Giovanni Vernacci. Así, por ejemplo, leemos en una de ellas: «me he vuelto inútil para mí, para los parientes y para los amigos, porque así lo ha querido mi dolorosa suerte» (carta 66). A ese momento, sin embargo, pertenece la importante epístola a Lodovico Alamanni, en la que Maquiavelo refiere indirectamente estar trabajando en su obra literaria:

He leído durante estos días el Orlando furioso de Ariosto, y ciertamente el poema es bello en general, y en muchos momentos admirable. Si anda por allí, encomendadme a él, y decidle que sólo me molesta que, recordando a tantos poetas, me haya ignorado como a un carajo, y que lo que él ha hecho conmigo en su Orlando, yo no lo haré con él en mi Asno (carta 69).

El tercer período distinguido por Forte (1520-1527) coincide con la lenta rehabilitación política de Maquiavelo, y se abre con el encargo por parte de los Medici para escribir la Historia de Florencia (carta 74), encomienda recibida gracias a la mediación de Francesco Guicciardini; sigue con el reconocimiento como comediógrafo de éxito por La Mandrágora, escrita en 1518, y como experto en asuntos militares a partir de la publicación de su tratado Del arte de la guerra (1521). Vuelve a recibir encargos diplomáticos y militares, pequeñas misiones que, pese a su modestia, le permiten reincorporarse a la vida política. Durante estos últimos años asistimos al intercambio epistolar con Guicciardini, capitán de las tropas de los papas Medici y gobernador de Módena. El contenido de dicho intercambio, muy diverso en su temática, es particularmente lúcido e inteligente. No hay que renunciar a la diversión ni en tiempos oscuros, recordaba sabiamente el amigo a Maquiavelo. Así, refiriéndose a los preparativos para la representación de La Mandrágora escribía Guicciardini: «Empezaré a responderos de la comedia, porque no creo que sea de lo menos importante que nos traemos entre manos, y al menos es un asunto que depende de nosotros, de manera que pensar en ello no es perder el tiempo; además, en un período de tanta turbulencia, el divertimento es más necesario que nunca» (carta 97).

Especial interés suscitan las cartas en que Maquiavelo analiza con gran lucidez la situación creada cuando el papa Clemente VII firmó la Liga de Cognac 
con el rey de Francia y los estados italianos, justo un año antes de producirse el saqueo de Roma. El 17 mayo de 1526 escribía a Guicciardini:

[...] acordaos de que la Fortuna, los malos consejos nuestros y los peores ministros hubieran conducido a prisión no ya al Rey [de Francia], sino al Papa. Nos libraron de ello los malos consejos de los otros y de nuevo la Fortuna. Proveed ahora, por el amor de Dios, para que S.S. no se vea expuesto a los mismos peligros, de lo que nunca estaréis seguro hasta que no se consiga expulsar a los españoles de Lombardía, y de tal modo que no puedan regresar [...]. Y recordad que el Duque de Sessa iba diciendo quod Pontifex sero Caesarum ceperat timere [que tarde el Pontífice aprendía a temer al Emperador]. Ahora, Dios ha reconducido las cosas a un punto en el que el Papa está a tiempo de frenarlo, siempre que no se pierda la oportunidad. Vos sabéis cuántas ocasiones se han perdido: no perdáis ésta, ni confiéis en manteneros donde estáis encomendándoos a la Fortuna y al tiempo, porque el tiempo no trae nunca las mismas situaciones, ni la Fortuna es siempre la misma (carta 101).

Mención aparte merece la conmovedora carta que dirigió a su hijo Guido en abril de 1527, en la que le aconseja: «Es necesario que tú aprendas, y, puesto que ya no tienes excusa para comportarte mal, que te apliques en el aprendizaje de las letras y la música, que ya ves cuánto me honra a mí esa poca virtud que tengo; de manera que, hijo mío, si tú quieres tenerme a mí contento, y beneficiarte y honrarte tú mismo, estudia, compórtate bien, aprende, que si tú te ayudas, todos te ayudarán» (carta 114).

Mucho ha interesado estos últimos años la naturaleza de la escritura epistolar de Maquiavelo. Algunas de sus cartas, como ya se ha indicado, se cuentan entre las más famosas de la literatura italiana. En Italia está en marcha, en este momento - a cargo de la editorial Salerno y dentro de la Edizione Nazionale delle Opere di Niccolò Machiavelli-, la edición de las Lettere, que seguramente añadirá un buen número de novedades y correcciones a las ediciones existentes. A falta de una edición crítica definitiva en italiano, Forte se ha basado particularmente en la de Franco Gaeta (Lettere, 1984, segunda edición), que contiene el texto más completo disponible hasta el momento; se ha servido asimismo de otras ediciones parciales, así como de las aportaciones de numerosos especialistas. Ha consultado y contrastado su traducción con las versiones de Luis A. Arocena (Cartas Privadas de Nicolás de Maquiavelo, Buenos Aires, 1979) y Stella Mastrangelo (Epistolario 1512-1527, México, 1990), ofreciendo una relación de las principales variantes adoptadas respecto de ambas traducciones. Toda la obra está anotada a pie de página, con la «información más escueta posible» (p. 42), intentando orientar a quien se adentra en ella en el laberinto de nombres y hechos aludidos; otras notas están dedicadas a señalar problemáticas textuales y las variaciones adoptadas. Para la anotación, Forte ha utilizado también la edición de Miguel Ángel Granada (Antología, Barcelona, 2002, reimpresión de la edición de 1987). La introducción se cierra con un elenco de la bibliografía empleada y un sumario cronológico donde constan, de forma abreviada, los principales acontecimientos de la vida y la obra 
de Maquiavelo junto con los sucesos políticos más importantes de la época. La edición se enriquece con un mapa político de Italia y unas magnificas ilustraciones que aluden a los argumentos más significativos del epistolario.

Así, casi repitiendo las palabras con las que comienza la presente nota, cabe saludar esta nueva edición de las epístolas privadas de Maquiavelo llevada a cabo, con precisión y cuidado, por Juan Manuel Forte. 